
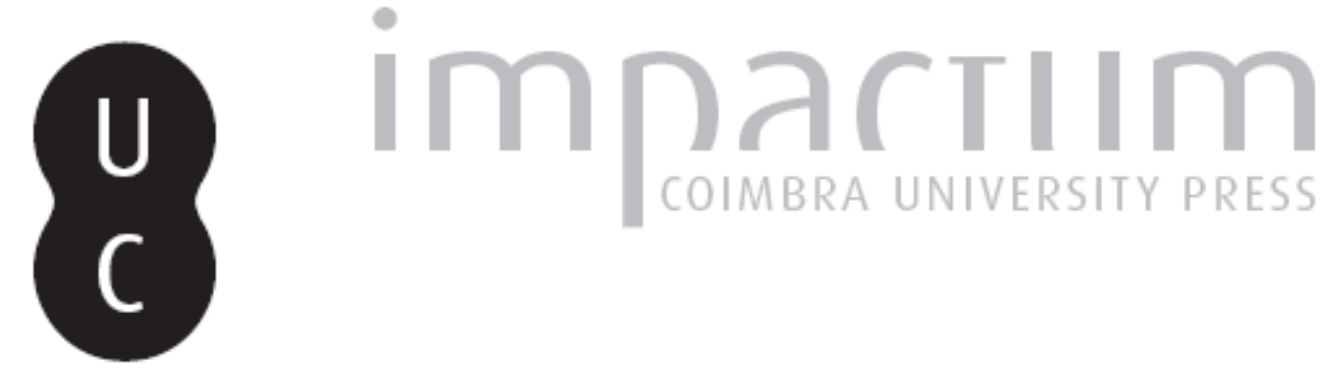

\title{
Leopardi e Fernando Pessoa: projeto e anteprojeto do "livro único" no Zibaldone e no Livro do Desassossego
}

Autor(es): $\quad$ Castro, Sílvio

Publicado por: Imprensa da Universidade de Coimbra

URL persistente:

URI:http://hdl.handle.net/10316.2/42582

DOI:

DOI:https://doi.org/10.14195/0870-8584_4_13

Accessed : $\quad$ 26-Apr-2023 16:28:04

A navegação consulta e descarregamento dos títulos inseridos nas Bibliotecas Digitais UC Digitalis, UC Pombalina e UC Impactum, pressupõem a aceitação plena e sem reservas dos Termos e Condições de Uso destas Bibliotecas Digitais, disponíveis em https://digitalis.uc.pt/pt-pt/termos.

Conforme exposto nos referidos Termos e Condições de Uso, o descarregamento de títulos de acesso restrito requer uma licença válida de autorização devendo o utilizador aceder ao(s) documento(s) a partir de um endereço de IP da instituição detentora da supramencionada licença.

Ao utilizador é apenas permitido o descarregamento para uso pessoal, pelo que o emprego do(s) título(s) descarregado(s) para outro fim, designadamente comercial, carece de autorização do respetivo autor ou editor da obra.

Na medida em que todas as obras da UC Digitalis se encontram protegidas pelo Código do Direito de Autor e Direitos Conexos e demais legislação aplicável, toda a cópia, parcial ou total, deste documento, nos casos em que é legalmente admitida, deverá conter ou fazer-se acompanhar por este aviso.

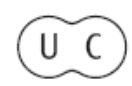




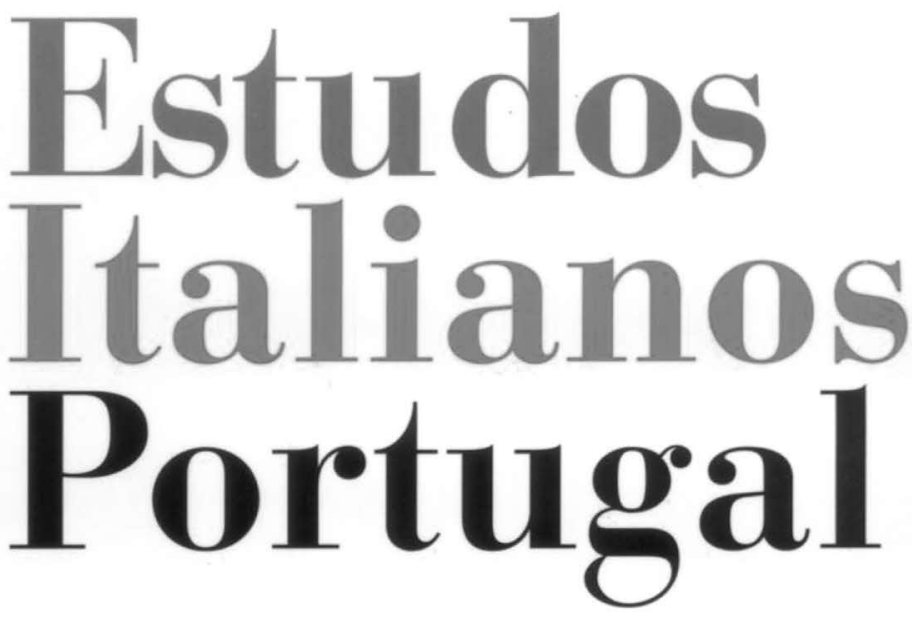

Instituto

Italiano

de Cultura

de Lisboa

Nova Série

$\mathbf{N}^{\mathbf{0}} 4$.

2009 


\section{LEOPARDI E FERNANDO PESSOA: \\ PROJETO E ANTEPROJETO \\ DO "LIVRO ÚNICO" NO ZIBALDONE \\ E NO LIVRO DO DESASSOSSEGO}

Sílvio Castro*

PARA QUE SE CRIE, com tenaz tomada de posição da vontade criadora, um projeto de escritura que se torne livro enquanto um "único", o escritor assim dinamizado deve necessariamente pensá-lo como superação de quanto de relativo até então lhe propiciara a sua prática da escritura. Ou mesmo, de quanto a mesma prática continuava a permitir-lhe na insone repetição criadora, pois à presença de outros livros nascentes ele não podia furtar-se.

O projeto do "livro único" se mostra imediatamente como sofrido processo do escritor diante de suas experiências retóricas, em particular diante daquelas referidas ao conceito de gênero. Quanto mais a capacidade criadora do escritor varia na prática dos gêneros literários, dela retirando a referência inicialmente indispensável à própria operação

* Sílvio Castro, poeta, romancista e contista, ensaísta, comparatista e cultor de teoria literária, crítico e historiador literário, crítico de arte, com mais de cinquenta volumes publicados. Bacharel e licenciado em Filosofia (1954-55) e Bacharel em Direito (1957). Transfere-se do Brasil à Itália, com residência em Veneza, a partir de 1962. Docente universitário. Livre-docente em "Literatura brasileira" e Doutor em Letras, pela UFRJ, Professor titular (aposentado) de "Lingua e Letteratura portoghese" e Titular-suplente de "Letteratura brasiliana" na Univ. de Padova. Docente-suplente por vários anos das mesmas disciplinas nas Universidades de Veneza e Pavia, bem como professor-visitante em diversas universidades do Brasil, Portugal e Itália. Tem no prelo o volume Poesia do Socialismo português. 
expressiva, mais essa mesma capacidade se vê condicionada e muitas vezes limitada. Ainda que diante de tudo isso a vontade criadora se rebele, ela não pode encetar a própria operação sem a ajuda do processo retórico aparentemente adequado, isso em face de sua mesma formação literária e do imponderável com que todo projeto artístico inicialmente se apresenta.

De certo modo, o projeto do "livro único" se mostra desde um seu início como uma forma de negação ostensiva por parte do autor quanto aos condicionamentos retóricos a que está sujeito diante do conceito de gênero literário que o guia. Nesse condicionamento metodológico o autor recai sempre a cada momento que sente o imperativo da liberação dos livros nascentes. Assim, o escritor tomado pelo projeto do "único" se vê, a um só tempo, condicionado pela metodologia retórica inicialmente consoladora e ansioso de desconsolos, isto é, de uma absoluta liberdade retórica.

Diante de uma tal situação estético-existencial, o projeto do "único" não reentra no rol dos livros nascentes, não sendo por isso mesmo um "livro". Possivelmente uma tal errança, feita mais de uma circunstancial não-propriedade metodológica que de capacidade de escritura, justifica a perda de um sentido cronológico fixo para a realização do projeto, o que igualmente logo permite vê-la como tradução de um anti-projeto do "único". A dimensão temporal passa a ser então um novo elemento retórico, permitindo ao autor do projeto ou do anti-projeto dar-se novas regras para a execução de sua obra fragmentária e sem fim.

Em verdade o autor não vive as dificeis peripécias das revolucionárias mudanças da retórica tradicional para a assunção daquela inovadora e indispensável à absoluta liberdade criadora a que se prende o atemporal projeto do "livro único". Mais que viver tais peripécias, ele convive com elas e por isso mesmo as supera. Assim pode acontecer porque o autor que perde a propriedade do tempo conquista aquela 
outra do espaço, a cada momento que engrandece o seu "livro" com um novo e diverso fragmento.

Além da grande, ainda que imponderável, dimensão conquistada com o "livro único", o autor se modifica também quanto aos outros livros nascentes, agora enriquecidos pela dura experiência dos fragmentos que se corporificam no espaço atemporal e servidos de processos metodológicos provocados por novas regras da retórica então aberta.

Tanto o Zibaldone, de Leopardi, quanto o Livro do desassossego, de Fernando Pessoa, traduzem com grande eficácia a complexidade teórica que tais projetos, enquanto "livro único", apresentam. Isso naturalmente mesmo tendo em vista as diferenças substanciais existentes entre os dois autores, diferenças também próprias dos tempos existenciais de cada um deles, mas principalmente resultantes da respectiva grandeza criadora que ambos os poetas souberam dar à obra pessoal ${ }^{1}$.

Muitas e evidentes são as linhas culturais condutoras que acomunam ou que dividem escritores como Leopardi e Pessoa na ambição do "livro único". De comum eles têm principalmente a consciência de uma metodologia-guia de natureza ambígua, portanto contrária a qualquer limitação de gêneros e ambiciosa de uma libertação dos cânones da retórica clássica; mas também a de uma outra, isto é, a consciência de uma possível realização dos respectivos projetos sem, entretanto, cuidar-se de uma assumida mesma

1 Para a melhor afirmação de uma nossa desejada teorização do "livro único", o Zibaldone e o Livro do desassossego, pelas muitas afinidades que os ligam, formam uma determinada e específica família do gênero. Naturalmente não são os únicos exemplos possíveis, mas são particularmente exclusivos. O que não impede que o livro de Leopardi encontre afinidades com outros seus antecedentes, em particular Pensées sur la religion et sur quelques autres sujets (1669), de Blaise Pascal (1623-1662), e Les confessions (1. ${ }^{a}$ parte, 1781; 2. ${ }^{a}$ parte, 1788), de Jean-Jacques Rousseau (1712-1778); o mesmo acontecendo com aquele de Pessoa, declaradamente ligado ao de Amiel. 
realização. Assim, para ambos o "livro único" é uma obra sempre em aberto, quase uma afirmação em desespero da própria existência. Por ser e estar próximo existencialmente do desespero, o "livro único" é quase quotidiano e como que tomado qual antídoto à absurda idéia da morte pessoal. Sendo assim, o "livro único" acompanha praticamente a vida do autor, ainda que objetivamente seu texto possa ter uma localização temporal certa ou quase certa, ou ainda porventura só aparente.

O Zibaldone tem a sua localização temporal certa: começa em $1817^{2}$. E principia como em suspensão de finalidades comunicativas mais amplas, senão aquelas tendentes ao universal, próprias do jovem e super-erudito Leopardi de dezenove anos, cultor dos clássicos e gênio filológico em plena floração:

Palazzo bello. Cane di notte dal casolare, al passar del viandante.

Era la luna nel cortile, un lato

Tutto si illuminava, e discendea

Sopra il contiguo lato obliquo un raggio...

Nella (dalla) maestra via s'udiva il carro

Del passegger che stritolando i sassi,

Mandava un suon, cui precedea da lungi

Il tintinnìo de' mobili sonagli.

Onde Aviano raccontando una favoletta dice che una donna di contado piangendo un suo bambolo, minacciogli se non taceva che l'avrebbe dato mangiare un lupo. E che un lupo che a caso di là passava, udendo dir questo alla donna credettele

2 O percurso histórico dos fragmentos que compõem o Zibaldone já se vê corporificada com a $1 .^{\text {a }}$ edição da obra, em 7 vols., organizada por uma comissão nacional de estudiosos, presidida por Giosuè Carducci, para os prelos da editora Le Monnier, Florença, 1898-1900, com o título Pensieri di varia filosofia e di bella letteratura. 
che dicesse vero, e messosi innanzi all'uscio di casa così stette quivi tutto quel giorno ad aspettare che la donna gli portasse quella vivanda. Come poi vi stesse tutto quel tempo e la donna non se n'arcorgesse e non n'avesse paura e non gli facesse motto con sasso o altro, Aviano lo saprà che lo dice. E aggiugne che il lupo non ebbe niente perché il fanciullo s'addormentò e quando bene non l'avesse fatto non ci saria stato pericolo. E fatto tardi, tornato alla moglie senza preda perché s'era baloccato ad aspettare fino a sera, disse quello che nell'autore puoi vedere. $^{3}$

O último fragmento, o de número 4526, é de 4 de dezembro de 1832, datado de Florença, quase cinco anos antes da morte do poeta, em Nápoles, no dia 14 de junho de 1837.

3 "Belo palácio. Um cachorro na noite do povoado, ao passar de um viandante. / Era a lua no pátio, de um lado / Tudo se iluminava, e descia / Sobre o contíguo lado oblíquo um raio... / $\mathrm{Na}$ estrada principal se ouvia o carro / Do passageiro que comprimindo as pedras / Mandava um som, ao qual de longe precedia / O tintinar das sinetas móveis. // Onde Aviano, ao contar uma pequena fábula diz que uma mulher do condado, chorando o filhinho, ameaçou-o que, se não parava de latir, o daria em pasto a um lobo. E que o lobo que por acaso ali passava, ouvindo o que dizia a mulher acreditou que ela dissesse a verdade, e metendo-se à porta da casa assim ficou por todo aquele dia, esperando que a mulher lhe trouxesse aquela comida. Depois, como ali ficasse por todo o tempo e a mulher disso nada notasse e não tivesse medo e não lhe fizesse ameaças com pedras e mais, Aviano de certo o saberá que o diz. E acresccnta que o lobo não obteve nada porque a criança adormeceu e quando teria acordado já não existiria mais perigo. E (o lobo) perdido o tempo retornou de encontro à companheira sem caça porque tinha perdido o tempo todo na espera, até a noite chegar, e disse (à companheira) aquilo que no autor poderás ver."

Flávio Aviano (sécs. IV-V), poeta latino, autor de 42 fábulas à maneira de Esopo. Todas as citações do "livro" leopardiano, como aqui e a partir daqui, são feitas da edição: Leopardi, Zibaldone (dir. de Lucio Felici, intr. de Emanuele Treve; índices filológicos de Marco Dondero; índice temático e analítico de Marco Dondero e Wanda Marra), Roma, Newton, 1997. Como regra de citação adotamos, a partir daqui, como o caso da chamada presente $(Z i b .4526)$ as sínteses $Z i b$. para o título do livro, acompanhado do $n .{ }^{\circ}$ do fragmento citado, no atual caso 4526 . 
Ao inicial tom do jovem erudito e filólogo clássico, agora predomina aquele do filósofo pessimista:

La cosa più inaspettata che accada a chi entra nella vita sociale, e spessisimo a chi v'è invecchiato, è di trovare il mondo quale gli è stato descritto, e quale egli lo conosce già e lo crede in teoria. L'uomo resta attonito di vedere verificata nel caso proprio la regola generale.

$\mathrm{Na}$ incansável realização de seu "livro único", Leopardi percorre as diversas etapas de uma personalidade cultural e artística de marcada grandeza. Inicialmente e em correspondência com a sua sofrida formação intelectual, caracterizada por uma precocidade que a todos surpreende, ele se apropria dos elementos mais significativos da cultura clássica, bem como de conhecimentos linguísticos convenientes a tal empresa, fazendo-se um notável especialista do latim e do grego. $\mathrm{O}$ quase menino Giacomo encanta não somente a sua platéia doméstica nas angustiantes sabatinas públicas na praça principal de Recanati, mas também os eruditos de toda Itália, pelas suas traduções dos clássicos. A sua preocupação inicial e formativa é, assim, diretamente conduzida à conquista da melhor dimensão de um filólogo clássico, a partir da qual a personalidade leopardina se plasma sob a égide da mais estrita consciência metodológica. Os fragmentos iniciais do Zibaldone traduzem tendencialmente tais características culturais do jovem intelectual. O espírito científico de uma tal formação, a conquista rara de uma metodologia correspondente com investigações as mais diversas, a constante integração na vida, acompanhada de uma visão tanto da dimensão pessoal, quanto daquela política, fazem com que em Leopardi se afirme igualmente uma indagação filosófica que se junta aquela filológica ${ }^{4}$.

4 O complexo pensamento filosófico de Leopardi, à base de toda a sua obra literária, servirá de elemento de estudos e de ampla provocação para as próprias 
Em seguida, quanto mais se estabiliza a linha filosófica, mais se acentua nele a passagem do empenho pela erudição a favor da literatura. $\mathrm{O}$ erudito ligado profundamente ao passado e à tradição se deixa conquistar pelas novas vias que a modernidade romântica projetava aos tempos revolucionados. Trata-se de um profundo, longo e sofrido percurso confiado ao "livro único".

Tudo isso nasce da capacidade de participação do humanista que desde cedo se revelara em Leopardi. Em proporção ao constante aprofundimento de seu pensamento filosófico e da correspondente acentuação da prática da poesia, ele se abre igualmente à análise social e ao sentimento político. Tudo confiado inicialmente ao metódico caos aparente das páginas do Zibaldone, para depois alargar-se nas diversas obras em prosa e nos poemas que fazem os Canti ${ }^{5}$.

$\mathrm{Na}$ grande operação leopardiana pela criação do "livro único" naturalmente o campo de interesse geral é vastíssimo, ainda que todo ele passível de ser visto a partir das linhas condutoras - a filológica, a filosófica e a literária - que sintetizam a personalidade global do autor. O campo de interesse geral do Zibaldone projeta, assim, um grande corpus tópico, do qual podemos retirar as tópicas mais diretamente condutoras do pensamento crítico de Leopardi (em caráter itálico registramos aquelas particularmente significativas para o possível projeto com que se apresenta o "livro"):

Aldilà (o além), allegrezza (alegria), altri e altruismo (os outros e altruismo), ambizione (ambição), amicizia (amizade), amore

reflexões filosóficas de Shopenhauer, conforme testemunhos escritos feitos pelo filósofo alemão. A dualidade "razão" e "vontade", essencial para o sistema shopenhauriano e da sua revolucionária proposta para o pensamento moderno, caracteriza grande parte dos fragmentos do Zibaldone.

${ }^{5}$ A força expressiva do Zibaldone pode ser igualmente aquilata pela sua irradiação em muitas das obras de Leopardi. Além de muitos poemas que compõem os Canti, igualmente em prosa, tal evento se verifica objetiva e metodologicamente, como para os Pensieri e para as Operette morali. 
(amor), amore universale (a. universal), amor patrio (a. pátrio), amor proprio (a. próprio), anima (alma), animo (ânimo), antichi e antichità (antigos e antiguidade), antichi e moderni (antigos e modernos), ardire (ousar), arte (arte), assoluto (absoluto), belle (belas), bellezza (beleza), bello (belo), bene (bem), bestie (béstias), bontà e buono (bondade e bom), brutezza e brutto (feiura e feio), carattere (caracter), cattolicesimo (catolicismo), cinquecentisti e cinquecento (quinhentistas e quinhentos), civiltà (civilização), classici (clássicos), commedia (comédia), compassione (compaixão), comunicazioni (comunicação), consolazione (consolação), contentezza (contentamento), coraggio (coragem), corpo (corpo), cristianesimo (cristianismo), cuore (coração), dei (deuses), delicatezza (delicadeza), desiderio (desejo), dimenticanza (esquecimento), Dio (Deus), dolore (dor), donna (mulher), dovere (dever), dramma e drammatica (drama e dramática), dubbio (dúvida), educazione (educação), egoismo (egoismo), eleganza (elegância), essere (ser), eternità (eternidade), fama (fama), filosofia (filosofia), futuro (futuro), genere umano (gênero humano), generi letterari (g. literários), genio (gênio), gioventù (juventude), gloria (glória), governo (governo), guerra (guerra), gusto (gosto), idea (idéia), illusioni (ilusões), imitazione (imitação), individuo (indivíduo), infelicità (infelicidade), infinito (infinito), ingegno (engenho, talento, gênio), invidia (inveja), letteratura (literatura), libertà (liberdade), lingua e linguaggio (língua e linguagem), linguaggio poetico (l. poético), materia (matéria), memoria (memoria), metafisica (metafisica), monarchia (monarquia), mondo (mundo), morale (moral), morte (morte), natura (natureza), nazione (nação), noia (tédio), nulla (o nada), odio (ódio), parola (palavra), piacere (prazer), poesia (poesia), poeta (poeta), religione (religião), politica (política), ragione (razão), relatività (relatividade), rimembranza (recordação), romantici (românticos), romanticismo (romantismo), sapere (o saber), scienza (ciência), scrittura (escritura), sensazioni (sensações), sentimento (sentimento), società (sociedade), solitudine (solidão), speranza (esperança), sublime (sublime), suicidio (suicídio), 
sventura (desventura), tempo (tempo), universo (universo), uomo (homem), vecchiezza (velhice), verità (verdade), vigore (vigor), virtù (virtude), vita (vida). ${ }^{6}$

\section{1) Percursos da formação de um pessoal pensamento FILOSÓFICO}

O Zibaldone contém tecnicamente um processo lógico e metódico, afirmativo de um pessoal pensamento filosófico. São evidentes as raízes histórico-culturais de tal pensamento, bem como os princípios que o caracterizam na sua forma definitiva e autônoma.

Qual exemplo de relacionamento entre filologia e filosofia, em adequada coerência com os interesses formativos do autor, interesses esses debruçados preferencialmente sobre a lição do passado e da tradição estabelecida, logicamente alargados ao pensamento moderno, a indagação leopardiana bebe de preferência nas lições dos filósofos pré-socráticos e, dentre esses, naqueles que acentuam uma particular dialética da linguagem a favor da realidade objetivamente quantificável e transmissível enquanto tal; isto é, os ditos "filósofos sofistas". Deles Leopardi toma o conceito de natureza que se faz centro absoluto de suas indagações, e dessas raízes sofistas possivelmente derivam as qualidades dialéticas do pensamento leopardiano, sempre ampliadas com o intensivo e aberto sistema retórico de que se serve o recanatense. Munido de tais instrumentos, o pensamento de Leopardi pode chegar às suas possíveis características estáveis e mais remarcáveis, realizando uma síntese crítica do sistema filosófico que tem particularmente em vista o desenvolvimento histórico das conquistas da razão especulativa, específico da

${ }^{6}$ Quanto a esta matéria, cf. os ótimos "Indici filologici", de Marco Dondero, e "Indice tematico e analitico", de Marco Dondero e Wanda Marra, in Leopardi, Zibaldone, ed. cit. 
ciência moderna, bem como a revolução representada pelo cristianismo confrontada com a tradição clássica. A partir de todos esses e de outros elementos, ele constrói um pensamento pessoal sobre a "qualidade da vida" ideal ou apenas possível, vivida ou sempre em perspectiva.

\subsection{Pensamento filosófico e Conceito de natureza}

A natureza é o centro do pensamento leopardiano e a sua metodologia.De certa maneira, a natureza é sempre perversa e inimiga do homem, mas este não pode prescindir dela. Mais que ação direta da natureza, o sentimento de infelicidade humana resulta do divórcio que esse mesmo homem estabeleceu com a natureza. À predominante consciência da infelicidade da vida, o homem pode somente opor a sua consciência positiva da natureza da qual se apartou. Assim fazendo, lhe serão possíveis aqueles raros momentos de felicidade de que pode gozar, mas certamente presente aquele outro pessoal e consolador da dimensão existencial.

La ragione è nemica d'ogni grandezza: la ragione è nemica della natura: la natura è grande, la ragione è piccola. Voglio dire che un uomo tanto meno o tanto più difficilmente sarà grande quanto più sarà dominato dalla ragione (Zib. 14-15)

La natura può supplire e supplisce alla ragione infinite volte, ma la ragione alla natura non mai, neanche quando sembra produrre delle grandi azioni; cosa assai rara: ma anche allora la forza impelente e movente, non è della ragione ma della natura. Al contrario togliete le forze somministrate dalla natura, e la ragione sarà sempre inoperosa e impotente. (Zib. 333)

La natura è vita. Ella è esistenza. Ella stessa ama la vita, e procura in tutti i modi la vita, e tende in ogni sua operazione alla 
vita. $[\ldots . . .$.$] Quello che noi chiamiamo natura non è princi-$ palmente che l'esistenza, l'essere, la vita, sensitiva o non sensitiva delle cose. Quindi non vi può essere cosa nè fine più naturale, né naturalmente amabile e desiderabile e ricercabile, che l'esistenza e la vita, la quale è quasi tutt'uno colla stessa natura, né amore più naturale, né naturalmente maggiore che quel della vita. (Zib. 3813-3814)

\subsection{Cristianismo, em geral e em relação ao conceito de NATUREZA}

O pensamento crítico de Leopardi em relação ao cristianismo se mede diretamente com a ênfase dada por ele mesmo ao valor e significado das culturas antigas e da tradição clássica para sua formação intelectual. Mesmo no plano diretamente religioso, tal crítica não se atenua, ainda que em várias oportunidades ele afirme uma convergência final entre o seu pensamento do mundo e aquele próprio das lições do cristianismo.

Mais que um ser religioso, Leopardi se auto-propõe principalmente para as dimensões próprias da moral e da ética. Do cristianismo, quase em paradoxo, ele retira muitas vezes as dimensões de sua visão materialista da existência e do comportamento individual, tendo sempre em vista a absoluta importância que dá ao mais amplo conceito de natureza:

E una delle gran cagioni del cangionamento nella natura del dolore antico messo col moderno, è il Cristianesimo, che ha solennemente dichiarata e stabilita e per così dire attivata la massima della certa infelicità e nullità della vita umana (Zib. 105)

il Cristianesimo non ha migliorato il mondo in quanto alla crudeltà, e all'uso della forza e della guerra, ma lo ha peggiorato, privando l'uomo dell'amor patrio (Zib. 898-900) 
La Religione Cristiana rivella infatti molti atributi di Dio che passano affatto e si oppongono all'idea che noi abbiamo dell'estensione del possibile (Zib. 1627)

Da che la perfezione del Cristiano è relativa a se stesso, da che l'esser perfetto include la fuga delle tentazioni, vale a dire del mondo, da che per conseguenza il ritiro è il perfetto stato dell'uomo, il Cristianesimo è distruttivo della società (Zib. 1687)

La legge cristiana è in contradizione con la natura, in quanto prescrive di amare Dio e il prossimo più e contro se stessi (Zib. 2232)

\subsection{Filosofia, literatura, Linguagem E POesia}

A importância da literatura, em geral, e da poesia, em particular, se apresentam em Leopardi como uma quase consequência da prática e frequência formativa de sua natureza filológica, da consequente conquista de um "gosto" estético específico e do desenvolvimento de seu pensamento filosófico. A união entre interesse filológico e desenvolvimento continuado da educação filosófica leva à particular valorização da dimensão literária. No processo leopardiano, no qual o conceito de natureza vem colocado acima daquele da razão enquanto movente da possível conquista da melhor dimensão existencial, à filosofia da linguagem cabe um posto de realce absoluto. A partir da linguagem se vai à máxima compreensão do fenômeno estético, o qual mais que dependente do conceito de "bello", de "bellezza", se colega com aquele de "bene", de "verità".

Dal niente in letteratura si passa al mezzo e al vero, quindi al raffinamento (Zib. 1) 
Toda literatura deriva da filosofia. Principalmente a poesia lírica deriva do pensamento filosófico. Porém, a poesia não é filosofia, mas praticamente o seu contrário:

quanto è più filosofica, tanto meno è poesia (Zib. 1229)

Sendo essencialmente um fenômeno de linguagem, a literatura não pode ser senão moderna:

L'anima della letteratura moderna è la filosofia (Zib. 3318-3338)

La letteratura se non è moderna, non è vera letteratura ( $Z i b$. 3461-3466)

Il poeta non imita la natura: ben è vero che la natura parla dentro di lui e per la sua bocca... Così il poeta non è imitatore se non di se stesso; altrimenti non fa poesia ma prosa. (Zib. 4372-4373)

Fernando Pessoa, ao confronto com Leopardi, não tem uma específica formação filológica e não é um filósofo. Mas, como o recanatense, é um poeta maior e uma grande personalidade de estudioso. O seu Livro do desassossego pertence à mesma família do Zibaldone, sendo como ele um dos máximos exemplos de procura positiva do ideal do "livro único". Uma procura que tem praticamente a duração de uma existência, como acontece para com os grandes livros de todas as épocas.

Pessoa trabalha praticamente toda vida no seu "livro", começando a partir de 1912-13, assim seguindo até próximo à morte, em 1935. Como acontece na realização do gênero, o plano de trabalho depende não de um método inflexível, mas de realizações que coincidem com as iluminações constantes sobre os mais variados problemas e circunstâncias. Daí, a formação natural de um aparente caótico corpus de tópicas 
as mais diversas. Porém, no caos pessoano, um elemento unitário se apresenta como guia expressivo da operação: a natureza literária. O Livro do desassossego traduz irresistivelmente a presença de uma personalidade literária absoluta. Tudo em coerente confluência com a vida de Fernando Pessoa. O "livro" pessoano é mais uma vez um exemplo de como o escritor português vive uma intensa operação estética, até mesmo em relação à grande questão da heteronimia. Começando por assinar os seus fragmentos com o ortônimo Fernando Pessoa, logo em seguida o poeta sente a necessidade de transferir a operação a um semi-heterônimo, Bernardo Soares. Segundo Pessoa, Bernardo Soares não tem a dimensão dos três maiores heterônimos de sua poesia, Alberto Caeiro, Ricardo Reis e Álvaro de Campos. Mas é uma derivação de seu eu criador, muito próximo da dimensão heteronímica. Isso porque, entre os dois não existe uma verdadeira diferença de estilo, ambos possuindo praticamente um mesmo sistema de linguagem. Ao contrário de quanto acontece com os poemas de Álvaro de Campos, Ricardo Reis e Alberto Caeiro:

Criei em mim várias personalidades. Crio personalidades constantemente. Cada sonho meu é imediatamente logo ao aparecer sonhado, encarnado numa outra pessoa, que passa a sonhá-lo, e eu não.

Para criar, destruí-me, tanto me exteriorizei dentro de mim, que dentro de mim não existo senão exteriormente. Sou a cena viva onde passam vários actores representando várias peças. $(\operatorname{LdD} 230 \mathrm{I})^{7}$

7 Fernando Pessoa, Livro do Desassossego (intr. e nova organização de textos de António Quadros), 2 vv. (. $1^{\mathrm{o}}$ vol. na 2. ${ }^{\mathrm{a}}$ ed.; $2 .^{\circ}$ vol., na 3. ${ }^{\mathrm{a}}$ ed.), Publicações Europa-América, Lisboa, s.d. Como acontece para as citações de o Zibaldone, para o "livro" de Pessoa seguimos as seguintes regras, conforme a atual primeira citação ( $L d D 230$ I), onde LdD está para Livro do desassossego; 230, o número da página do fragmento citado; I, o volume correspondente). 
O Livro do desassossego, até mesmo quanto a sua autoria declarada, mais uma uma vez revela como o grande sistema pessoano de composição entre ortonimia e heteronimia é por excelência uma convicção radicalmente literária. A mesma que caracteriza a natureza exemplar do procurado "livro único" mais significativo da língua portuguesa.

\section{O LiVRo do DESASSOSSEgo COMO ESPAÇO DE CONFISSSÃo EXISTENCIAL}

A genial operação pessoana, exemplo ímpar de obra sempre aberta, se mostra naturalmente como uma confissão. Pessoa se mostra completamente diante do texto escrito, realizando uma como moderna operação de auto-análise, na qual o eu-sujeito atinge a força de chegar além de si mesmo. Porém, trata-se de uma confissão absolutamente laica, de quem prescinde de qualquer apoio metafisico ou religioso para chegar à própria análise:

Nasci em um tempo em que a maioria dos jovens haviam perdido a crença em Deus, pela mesma razão que os seus maiores a haviam tido - sem saber porquê. E então, porque o espírito humano tende naturalmente para criticar porque sente, e não porque pensa, a maioria desses jovens escolheu a Humanidade para sucedâneo de Deus. Pertenço, porém, àquela espécie de homens que estão sempre na margem daquilo a que pertencem, nem vêem só a multidão de que são, senão também espaços que há ao lado. Por isso nem abandonei Deus tão amplamente como eles, nem aceitei nunca a Humanidade. Considerei que Deus, sendo improvável, poderia ser; podendo pois dever ser adorado; mas que a Humanidade, sendo uma mera ideia biológica, e não significando mais que a espécie animal humana, não era mais digna de adoração do que qualquer outra espécie animal. (LdD 47 I e LdD 89 II) 
A intensa, ativa laicidade pessoana, crítica de todos os valores imediatamente indemonstráveis, por isso mesmo convive com a angústia existencial que caracteriza muitos dos representantes mais significativos da modernidade novecentista. Uma angústia que se faz ao mesmo tempo método de indagação da mesma angústia e que traduz uma existência que não pode ser confundida com outra qualquer. Angústia que se traduz metodologicamente a partir das mais distintas tomadas de consciência existencial ${ }^{8}$. Até aquela centralizante da constante relação entre vida e morte:

O homem não deve poder ver sua própria cara. Isso é o que há de mais terrível. A Natureza deu-lhe o dom de não poder ver, assim como de não poder fitar os seus próprios olhos. Só na água dos rios e dos lagos ele podia fitar seu rosto. E a postura, mesmo, que tinha de tomar, era simbólica. Tinha de se curvar, de se abaixar para cometer a ignomínia de se ver.

O criador do espelho envenenou a alma humana. (LdD 221-22 I)

A morte? Mas a morte está dentro da vida. Morro totalmente? Não sei da vida. Sobrevivo-me? Continuo a viver.

O sonho? Mas o sonho está dentro da vida. Vivemos o sonho? Vivemos. Sonhamo-lo apenas? Morremos. E a morte está dentro da vida. (LdD 56 II)

8 As raízes do pensamento filosófico de Pessoa enfocam, entre outras, duas grandes fontes aparentemente contraditórias: Kierkegaard e Nieztsch. O possível existencialismo leigo de Pessoa tem muitas afinidades com aquele profundamente religioso do filósofo dinamarquês, numa aparente manifestação de contradições que não são senão consequência da dimensão ilimitada que vem dada à força da dúvida e da angústia no poeta português. Esta mesma incontida dimensão o aproxima do pensamento radical do filósofo alemão e com ambas ele projeta seu sonho de modernidade. Sobre a modernidade de Pessoa e o conceito de modernidade, veja-se Sílvio Castro, " Modernismo, a questão filosófica da modernidade e o Livro do desassossego, de Fernando Pessoa”; cf. Bibliografia, abaixo. 


\section{Sobre a importância da literatura e natureza da POESIA}

A laicidade própria de Fernando Pessoa encontra na literatura o ponto central para a sua completa tradução. Somente com a literatura é possível a tradução do mundo real e consequentemente de uma conquista de consciência da própria angústia existencial. A literatura é a revelação da realidade, e o sonho é o instrumento privilegiado do poeta para a melhor revelação desse mesmo mundo. A revelação se completa quando o poeta, na máxima intensidade de aplicação de seu método existencial, se sente como que inexistente diante do mundo finalmente revelado:

Sabemos bem que toda obra tem que ser imperfeita, e que a menos segura das nossas contemplações estéticas será a de aquilo que escrevemos. ( $L d D 48 \mathrm{I})$

Toda a literatura consiste num esforço para tornar a vida real. Como todos sabem, ainda quando agem sem saber, a vida é absolutamente irreal na sua realidade directa; os campos, as cidades, as ideias, são coisas absolutamente fictícias, filhas da nossa complexa sensação de nós mesmos. São intransmissíveis todas as impressões salvo se as tornarmos literárias. (LdD 94 I)

Estou hoje lúcido como se não existisse. (LdD 93 I)

\section{Sobre o sistema do pensamento pessoano}

A mais direta manifestação do sistema pessoano se encontra na extrema valorização do tempo presente. No presente ele vê a modernidade que, mesmo não desconhecendo os significados mais positivos dos tempos passado e futuro, 
elide-os na absoluta afirmação da realidade imediatamente vivida:

Vivo sempre no presente. O futuro o conheço. O passado já o tenho. (LdD $90 \mathrm{I})$

A constante afirmação da realidade vivida faz com que o poeta debruçado diuturnamente sobre a sua angústia existencial assuma as mais distintas experiências do próprio eu e da tomada consequente do mundo exterior:

Como alguém que, de muito alto, tente distinguir as vidas do vale, eu assim mesmo me contemplo de um cimo e sou, com tudo, uma paisagem indistinta e confusa. (LdD 76 I)

Toda essa operação se concretiza na dramática síntese de "a consciência da consciência”, conquistada como máxima síntese de solidão existencial:

O diário de Amiel doeu-me sempre por minha causa.

Quando cheguei àquele ponto em que ele diz que sobre ele desceu o fruto do espírito como sendo "a consciência da consciência”, senti uma referência directa à minha alma. (LdD 54 I)

5. Sobre a relaÇão COM o “OUtro” E a CONSCiÊnCia POLÍTICO-SOCIAL

A solidão existencial de Fernando Pessoa encontra na presença igualmente existencial do "outro" o fator de si mesma. O “outro" não pode ser senão razão de desencontros, mas ele existe sempre na consciência do solitário e, mesmo "ausentado", condiciona a visão ética e as dúvidas político-sociais do poeta angustiado. Pessoa sofre e combate quotidianamente com a realidade exterior que procura condicionar a dimensão 
objetiva e sonhada de sua existência. O "outro" lhe mostra somente propostas que ele não busca na sua indagação mais pessoal, seja através da mulher que poderá jamais amar ou possuir ${ }^{9}$, seja igualmente nas provocações que a sociedade lhe faz para que se integre na comunhão do interesse comum. Por isso mesmo, muitas vezes Pessoa deve comportar-se em estado de reação às mensagens políticas e à dimensão do social feita do altruismo que ele rejeita metodicamente. Mas quanto mais nega a participação, mais se aprofunda na criação de todos os elementos de liberdade que a sua genialidade poética investiga e exprime como atos de liberação, não só para si, mas principalmente para a vida do "outro" convidado sempre a assumir o máximo de liberdade existencial ${ }^{10}$. Pessoa então assume a sua natural posição de agente da modernidade, ainda que para isso pague sempre a quase destruição de sua própria e passageira identidade. E assim vive sempre, porque a vida não pode ser percebida senão com angústia:

Conviver com os outros é uma tortura para mim. E eu tenho os outros em mim. Mesmo longe deles sou forçado ao seu convívio. Sozinho, multidões me cercam. Não tenho para onde fugir, a não ser que fuja de mim. A impossibilidade do encontro com o outro ( $L d D 42 \mathrm{II})$

Leopardi e Pessoa souberam construir inéditos projetos do "livro único". Para eles este era o sonho de conquista do máximo de criação. Mas, sendo a mesma uma operação

9 Ainda neste ponto, o do amor por uma mulher escolhida, apresenta notáveis pontos de contactos e, ao mesmo tempo, de distinção entre Fernando Pessoa e Kieerkegaard. A Ofélia pessoana é distinta em tudo da Regina Olsen kiekeegaardiana.

${ }_{10}$ Ao contrário de determinada crítica às idéias de Pessoa, em particular quanto uma sua possível ideologia reacionária, eu vejo nele um pensador essencialmente democrático. Esta minha posição eu a exponho no meu estudo A poesia do Socialismo português (no percurso de 1850 a 1974), Lisboa, a sair. 
fragmentária e naturalmente efêmera, ambos os poetas partem da obra impossível para a realização daquelas fatíveis.

Leopardi alarga os fragmentos de seu Zibaldone em ensaios e sínteses que traduzem momentos culminantes de uma prosa nova, metodologicamente guiada por uma cultura clássica aberta às provocações significativas da modernidade romântica. Porém, igualmente nos seus poemas dos Canti se reversa a constante investigação criativa do "livro único". Dentre esses poemas, pode-se escolher como exemplo "L'Infinito", no qual se substancia em forma genial aquele tema da superação de todos os limites de sensações através da conquista poética da dimensão infinita. Debruçado num dos pontos altos e isolados de sua solidão nas colinas natais de Recanate, o poeta contempla o espaço ilimitado e nele entra para atingir o máximo de percepção do mundo:

\section{Leopardi, L'infinito}

Sempre caro mi fu quest'ermo colle, E questa siepe, che da tante parte Dell'ultimo orizonte il guardo esclude. Ma sedendo e mirando, interminati Spazi di là da quella, e sovrumani Silenzi, e profondissima quiete Io nel pensier mio fingo; ove per poco Il cor non si spaura. E come il vento Odo stormir tra queste piante, io quello Infinito silenzio a questa voce Vo comparando: e mi sovvien l'eterno, E le morte stagioni, e la presente E viva, e il suon di lei. Così tra questa Immensità s'annega il pensier mio: E il naufragar m'è dolce in questo mare. ${ }^{11}$

11 Leopardi, "L'Infinito", Canti (org. de Giorgio Ficara, com um texto de Giuseppe Ungaretti) 21. ${ }^{a}$ reimpressão, Milano, A. Mondadori, 2008. 
Leopardi, O infinito

Sempre caro me foi este ermo monte, e esta sebe que de tantas partes do último horizonte a vista exclui. Mas, sentando e mirando infindáveis espaços de além e sobreumanos silêncios e fundíssima quietude, eu no pensamento me figuro, e quase o coração se espanta. Como o vento ouço voar entre essas plantas, eu aquele infinito silêncio a esta $\mathrm{voz}$ vou comparando, e me pulsa o eterno, e as mortas épocas, e a presente e viva, e o som dela. Assim nesta imensidade meu pensar se afoga: e o naufragar me é doce neste mar. ${ }^{12}$

Também Fernando Pessoa transfere em muitos de seus poemas, sejam ortônimos ou heteronímicos, sínteses fugazes do Livro do desassossego. E nele também vigora, ainda que em dimensão nova e pessoal, a ansiedade pela dimensão infinita. Essa agora tem características de uma diversa modernidade, na qual a constante romântica age como base para a elaboração incontida de todas as expressões de uma pesquisa poética que se renova sempre na criatividade dos muitos ritmos inéditos e que se faz palavra capaz de traduzir a angústia do mundo. Tudo pela integração pessoana com esse mesmo mundo, finalmente captado pela participação infinita do poeta criador com as sensações que o angustiam. Sensacionismo e modernidade:

12 Leopardi, O infinito, tradução de Sílvio Castro, in "Problemas diretos e questões indiretas sobre minha versão em português de L'infinito de Leopardi"; cf. Bibliografia. 
Fernando Pessoa, Impressões do crepúsculo

Pauis de roçarem ânsias pela minh'alma em ouro...

Dobre longínquo de Outros Sinos... Empalidece o louro Trigo na cinza do poente... Corre um frio carnal por minh'alma...

Tão sempre a mesma, a Hora!... Balouçar de cimos de palma!...

Silêncio que as fôlhas fitam em nós... Outono delgado

Dum canto de vaga ave... Azul esquecido em estagnado...

Oh que mudo grito de ânsia põe garras na Hora!

Que pasmo de mim anseia por outra coisa que o que chora!

Estendo as mãos para além, mas ao estendê-las já vejo

Que não é aquilo que quero aquilo que desejo...

Címbalos de Imperfeição... Ó tão antigüidade

A Hora expulsa de si-Tempo! Onda de recuo que invade

$\mathrm{O}$ meu abandonar-me a mim próprio até desfalecer,

E recordar tanto o Eu presente que me sinto esquecer!...

Fluido de auréola, transparente de Foi, ôco de ter-se...

O Mistério sabe-me a eu ser outro... Luar sôbre o não conter-se...

A sentinela é hirta - a lança que finca no chão

É mais alta do que ela... Para que é tudo isto... Dia chão... Trepadeiras de despropósito lambendo de Hora os Aléns... Horizontes fecham os olhos ao espaço em que são elos de êrro...

Fanfarras de ópios de silêncios futuros... Longes trens...

Portões vistos longe... através de árvores... tão de ferro! ${ }^{13}$

13 Fernando Pessoa, "Impressões do crepúsculo", de Cancioneiro, in Obra poética (organização, introdução e notas de Maria Aliete Galhoz), Rio de Janeiro, Aguilar, 1965. 


\section{BiBLIOGRAFIA}

Castro, Sílvio, "Problemas diretos e questões indiretas sobre minha versão em português de 'L'Infinito', de Leopardi”, in Revista Portuguesa de Humanidades, Outono de 2005, pp. 403-12. Igualmente in AA.VV., Studi in ricordo di Carmen Sanchez Montero (org. de Graziano Benelli e Giampaolo Tonini), 2 vv., Triestre, Scuola Superiore di Lingue Moderne per Interpreti e Tradutori-Università di Trieste, 2006; vol. 1, pp. 75-84.

- "Modernismo, a questão filosófica da modernidade e o Livro do desassossego, de Fernando Pessoa", in A ordem, Rio de Janeiro, 2007. Igualmente in Revista Portuguesa de Humanidades (n. ${ }^{\circ}$ especial pelo 10..$^{\circ}$ ano da revista), 2002; pp. 431-457.

Guerini, Andréia, Gênero e tradução no Zibaldone de Leopardi, São Paulo-Florianópolis, EDUSP-UFSC/PGET, 2007.

Habermas, Jürgen. Il discorso filosofico della modernità. Dodici lezioni (tr. it. de Emilio Agazzi), 2. ${ }^{a}$ ed., Bari, Laterza (tit. or.: Der philosophische Diskurs der Moderne. Zwölf Vorlesungen).

Leopard, Giacomo, Zibaldone (premessa di Emanuele Trevi, indici filologici di Marco Dondero, indice tematico e analitico di Marco Dondero e Wanda Marra - Edizione integrale diretta da Lucio Felici), Roma, Newton\&Compton, 1997.

- Operette morali, intr. e notas de Saverio Orlando, Milano, Rizzoli, 2. ${ }^{\mathrm{a}}$ ed., 1980.

- Pensieri, org. e intr. de Cesare Galimberti, Milano, Adelphi, 1982.

- Pensieri, intr. de Paolo Ruffilli, pref. e notas de Ugo Dotti, Milano, Garzanti, 1985.

- Poesia e prosa (organização e notas de Marco Lucchesi, traduções de Affonso Félix de Sousa, Alexei Bueno, Álvaro Antunes, Ana Thereza Vieira, Edson Rosa da Silva, Ivan Junqueira, Ivo Barroso, José Paulo Paes, Maurício Dias, Vera Horn, Vilma Barreto de Souza), Rio de Janeiro, Nova Aguilar, 1996.

PessoA, Fernando, Livro do desassossego, recolha e transcrição de Maria Aliete Galhoz e Teresa Sobral, org. e intr. de Jacinto do Prado Coelho, Lisboa, Ática, 1982.

- Livro do desassossego (por Bernardo Soares), intr. e nova organização de textos de António Quadros, 2 vols. 1. ${ }^{\mathrm{a}}$ parte, 2. ${ }^{\mathrm{a}}$ ed.; 2. ${ }^{\mathrm{a}}$ parte, 3. ${ }^{a}$ ed.; Lisboa, Europa-América, s.d. 
- Livro do desassossego, ed. Companhia das Letras, São Paulo, 1999. Richards, Ivor Armstrong, La filosofia della retorica (tit. orig. The Philosophy of Rhetoric), tr. it. de Beniamino Placido, Milano, Feltrinelli, 1967.

SChopenhauer, Arthur, Il mondo come volontà e rappresentazione, 2 vols., (tit. orig. Die Welr als Wille und Vorstellung), tr. it. de Sossio Giametta, Milano, Rizzolli, 2002. 